\title{
Socio-economic patterns of sport demand and ageing
}

\author{
Christoph Breuer • Kirstin Hallmann • Pamela Wicker • \\ Svenja Feiler
}

Received: 23 July 2010 / Accepted: 4 August 2010 / Published online: 12 August 2010

(C) European Group for Research into Elderly and Physical Activity (EGREPA) 2010

\begin{abstract}
Due to the demographic situation in nowadays societies, physical activity, and sport expenditure have to be analysed from a demographic as well as socioeconomical perspective. This means that determinants such as age, gender, nationality/ethnicity, income, time, educational level, profession, and social status have to be taken into account. However, when comparing the various studies, the different methods of analysis and different operationalisation of variables have to be considered. This is in particular vital investigating age. Whilst cross-sectional studies point out that physical activity generally decreases with increasing age, longitudinal analyses come to different results. Previous studies indicate that pertaining to gender more men take part in sports than women. However, considering period and cohort effects, recent longitudinal studies showed that women participate more in sport than in the past. Besides, it was found out that men generally tend to spend more money on sports than women do. A further finding is that the educational level influences physical activity positively. Research revealed that income had a positive impact on both, physical activity and sport expenditure.
\end{abstract}

Keywords Sport participation · Physical activity . Leisure economics

C. Breuer $\cdot$ K. Hallmann $(\bowtie) \cdot$ P. Wicker $\cdot$ S. Feiler Institute of Sport Economics and Sport Management, German Sport University Cologne,

Am Sportpark Müngersdorf 6, Cologne 50933, Germany

e-mail: k.hallmann@dshs-koeln.de

\section{Introduction}

The demand for sport has a dynamic character which can be observed in the demand for different sports (e.g. mountain biking or ski cross became more and more popular in recent years) and taking part in sport over the lifespan. Age, in particular, plays a crucial role investigating physical activity and sport expenditure considering the demographic shift and the ageing society nowadays. For instance, in the past, physical activity decreased substantially when people started working professionally. In contrast, in recent years, evidence for an increasing number of older people and more women taking part in sport has been found [3, 12]. Sport participation and physical activity in general can, inter alia, be explained from a demo-economical perspective $[11,25]$. This means that demographic (e.g. age and gender) as well as economic factors (e.g. income) are considered as determinants of physical activity. Furthermore, socio-economic factors can have an impact on physical activity. In this regard, the socio-economic perspective includes factors such as education, profession, employment, income, property, and culture. In contrast to the pure sociological perspective, the socio-economical perspective is an interdisciplinary field which uses economical factors to explain the social reality in societies [23].

The purpose of this paper is to give an overview about the main socio-economic indicators of physical activity and sport expenditure thereby focusing on age effects. The structure of this contribution is as follows: first, a short overview about the understanding of physical activity and meanings of age, period, and cohort effects will be shown in the theoretical background. Second, the current state of literature regarding a socio-economic perspective on physical activity will be discussed. Third, the socio-economic 
perspective will be applied to sport expenditure. In both parts, a focus will be laid on variables which are most commonly used in studies reviewed in this paper, however especially emphasizing age effects. Those are demographic variables such as age, gender, and nationality/ethnic background/migration background, e.g. [11], as well as economic determinants, e.g. [30]. Regarding the latter, especially income, time, and education (i.e. in some studies human capital) are presented. Human capital in this regard refers to the Beckerian approach [4].

\section{Theoretical background}

Physical activity

However, before coming to the review parts, it is necessary to clarify and define some terminology which is used throughout this review paper. Physical activity is defined dissimilar in different studies. Some researchers include sports and further activities such as gardening, home exercise, and walking the dog $[30,32]$, whilst other studies define physical activity as leisure time activities with an increase of the heart rate [48]. Therefore, with all these different definitions, it is hard to find a way to compare this heterogeneous amount of research. However, a useful description of physical activity for this research is the one by Sport England [55] which defines that sport is a moderate intensity activity of at least 30 -min duration at least once in a week. They further adapt the description of sport from the Council of Europe [24]. It states that sport comprises all forms of physical activity which aim at expressing or improving physical fitness and mental wellbeing as well as forming social relationships or obtaining results in competition at all levels [53]. Therefore, sport participation can be considered as physical activity. This definition given, a wide range of physical activities can be covered for this review.

Age, period, and cohort effects

Furthermore, to understand the different conducted studies, it is vital to understand the meaning of age, period, and cohort effects. Age is considered to have no explanatory power although it is a central scientific category. Therefore, age is a proxy variable for the totality of all possible agebased influences on physical activity $[10,12]$. In this respect, four factors of age with regards to physical activity can be differentiated: (1) the physical factor, meaning that increasing age is associated with decreasing health and physical performance; (2) the mental factor, meaning changes in motivation and attitude towards physical activity with increasing age; (3) the social factor, meaning age norms which convey the image of active or inactive elderly people as socially acceptable and different perceptions of body images; and (4) the economic factor, meaning changes in individual time and money depending on age.

Period effects are the influences of historical events and social changes on physical activity and they are responsible for an unstable development of sport and physical activity over time. Age and cohort are affected by period effects. As age, period is a proxy variable which needs further social and economical factors to gain explanatory power. (1) The social period factor includes changes in social norms and values, e.g. new ideals for body mass and slimness. (2) The economic period factor takes into account changes in infrastructural, financial, and temporal resources for sport activity (e.g. changes in sport supply, retirement, unemployment, etc.).

Cohort effects can be described as the influences of historical events and social changes on physical activity, similar to period effects. However, the difference is that cohort effects are cohort-specific, meaning that only a few cohorts (age groups) are really affected by the historical events taking place in a certain period and other age groups are not. Like age and period, cohort is a proxy variable with no explanatory power itself. Also in this case, the same social and economic factors apply as in period effects with the difference that they affect the preferences and resources of physical activity only in certain age groups.

\section{Socio-economic perspective on physical activity}

Regarding the research in sport science, there are only few studies which deal integratively and methodologically consistent with effects of demographic and economical changes on physical activity [7]. The determinants of sport participation in general have been investigated in numerous previous studies [e.g. 2, 5, 19, 22, 35]. Moreover, studies have also been conducted which deal with physical activity and ageing [14, 50, 52]. Dishman [18], for example, explores determinants of physical activity and exercise for persons of 65 years and older. However, precise discussions on age effects alone have been neglected as age is in most studies used as a proxy variable that is always investigated together with other variables as it has no explanatory power alone [12]. Furthermore, some studies rather deal with the physical activity level of the elderly with regards to health and biological functioning than with economical factors [20, 43]. Mechling and Netz [43] for example investigate physical activity in terms of increasing positive aspects and decreasing risks regarding life expectancy, fitness, and well-being. Pertaining to Germany, data sets on sport participation of people aged over 70 years are scarce. Nonetheless, few studies include specific aspects such as 
what kind of activities have been performed, in which frequency, intensity, and duration as well as what reasons are there for non-participation of the elderly [28]. However, one could assume that a reason for the decline in participation with increasing age can be ascribed to the fact that general health and physical fitness level decline with increasing age, as pointed out for example by Mechling and Netz [43] and Hinrichs et al. [28].

In the following, studies with demographic variables such as age, gender, and nationality will be reviewed to show which effects these variables have on sport participation. Second, the focus will be on economic indicators like income, time, and human capital (i.e. level of education) to detect how these indicators influence physical activity (Table 1).

Demographic determinants: age, period, cohort, gender, and nationality

Reviewing studies with regards to physical activity and ageing, or in other words, lifespan research, different results were obtained regarding sport participation. Those variations refer to the method of analysis which was used. The different methods employed to analyse physical activity over a life-span include cross-sectional analysis, longitudinal analysis, cohort-sequence analysis, and multipoint cross-sectional studies [10]. As a consequence, it is vital to take into account the different analytical tools which have been applied in the various studies when comparing the results, as pointed out by Breuer and Wicker [12].

Researchers who used cross-sectional studies, e.g. [28, 37] generally assume that sports activity and participation decrease with increasing age. This is confirmed by several findings in different studies, e.g. [5, 32, 61] and it applies also to different countries, for example Greece, [1] the USA [48], Switzerland [37], and further countries such as Italy, Spain, Ireland, Great Britain, the Netherlands, Sweden, and Finland [27]. The conclusion that physical activity decreases with increasing age cannot be drawn as the result might be for instance due to a mixture of age, period, and cohort effects. It has to be taken into consideration that age represents in this context a proxy variable indicating agebased influences on the physical, mental, social, or economic level.

Nonetheless, most studies in this area use a cross-sectional design. Breuer and Wicker [12] argue that cross-sectional analysis tend to be inadequate with regards to age effects as age and cohort effects are combined and only period effects can be controlled. Therefore, cross-sectional studies are not useful to give information about the development and stability of physical activity in a lifecycle. This represents however not only a deficit within sport science research but within social science in general. For instance, in demographic research, the focus lied until recently on cohort effects only whilst sociology investigated primarily period effects due to the general interest in social changes [42]. To overcome the shortcomings of cross-sectional analysis, other researchers used longitudinal analysis with regards to the ageing population [45] for example examined how physical exercise habits change during retirement years and how these changes can be assigned to health and socio-economic status. Further longitudinal studies found opposite results to the cross-sectional studies regarding the development of physical activity over a lifespan, e.g. [14]. Moreover, longitudinal analyses revealed that not age but cohort effects are responsible for decreasing sport participation [12]. Additionally, although longitudinal studies control for cohort effects, they mix age and period effects.

The most appropriate form to use in lifespan research is the cohort sequence analysis or a multipoint cross-sectional study [6]. In the cohort sequence analysis, the same population of different cohorts is analysed several times. Regarding the multipoint cross-sectional studies, different people of different years of birth are questioned on at least two measuring points.

In their study about the question if sports activity decreases with increasing age, Breuer and Wicker [12] used a longitudinal and cohort sequence analysis. The data was drawn from the German Socio-Economic Panel and with a data record of about 20 years, the development of sports activity could be analysed over a lifespan. The authors defined sports activity for their study as all forms of physical activity that aim at expressing or improving physical fitness or mental health, form social relationships or take part in sporting competitions (which goes along with the definition mentioned above in the introduction). They conducted the study on the above mentioned background that cross-sectional studies tend to be inadequate with regards to the control of age and cohort effects. In contrast to the findings of many cross-sectional studies, the longitudinal analysis revealed that sports activity actually increases with increasing age. Furthermore, they found through cohort sequence analysis that next to age, also cohort and period effects influence sports activity.

Pertaining to age also with regards to sport participation, Humphreys and Ruseski [30] found that each additional year of age reduces the probability that an individual participates in sport by $0.3 \%$. The probability of participation in physical activity increases with educational level and further, females are less likely to participate in sport than males. The effect of gender is similar in general studies on sport participation which reveal that males are considerably more likely to take part in sports than females $[5,25$, 30, 31, 40, 49, 59].

This is also found by Taks and Scheerder [59] who state that age and gender among young people are strong 
Table 1 Studies on sport participation (in chronological order)

\begin{tabular}{|c|c|}
\hline Author & Aim and method of the study \\
\hline $\begin{array}{l}\text { Pohjolainen and Heikkinen } \\
\text { [45] }\end{array}$ & $\begin{array}{l}\text { Longitudinal analysis of socio-economic status } \\
\text { and health on change in physical activity during } \\
\text { retirement years (Finland); } n=4 \text { interviews } \\
\text { (over } 12 \text { years }=n=134 \text { ); chi-square analysis and } \\
\text { correlations; problem of panel mortality. }\end{array}$ \\
\hline Farrell and Shields [25] & $\begin{array}{l}\text { Investigation of impact of economic and } \\
\text { demographic factors (age, ethnicity, education, } \\
\text { and health) on sport participation (England); } \\
n=6,467 \text {; random effects probit models that take } \\
\text { into account unobservable household preferences, } \\
\text { demographic, and economic characteristics. }\end{array}$ \\
\hline
\end{tabular}

Central findings

Most popular types of physical activity: walking, callisthenics, and swimming - dignificant decrease of physical activity after the age of 74 yearsphysical activity correlated with good health, status, and income.

Decrease of participation with increasing age, for men even stronger than for women-men more likely to participate in sport-women have different preferences regarding the type of sport-married people participate less in sport than singles - ethnic minorities participate less in sports than whitesnegative effect of poor health - positive impact of household income and education - unemployed participate more in sports.

Breuer [7]

Humphreys and Ruseski [30]

Cohort sequence analysis of income, time, human capital, age, immigration, cohort, period on sport participation (Germany); Longitudinal data $(n=3,782)$, cohort analysis $(n=98,772)$; regression analysis.

Examination of economic determinants (income and time) of participation and physical activity (USA); $n=175,246$; Heckman model.

Sport England [54]

Analysis of the determinants of participation (and non-participation) in sport and physical activity among elderly people (England); Qualitative, 21 focus groups (each $n=6-8$ ).

Downward and Riordan [22] Analysis of social interactions and motivations that affect sport participation (UK); $n=14,819$; cluster analysis and Heckman model.

\section{Lera-López and Rapún-Gárate [40]}

Breuer and Wicker [11]

Breuer and Wicker [12]

\section{Analysis of socio-demographic and economic variables regarding sport participation and consumer expenditure (Spain); $n=700$; ordered probit models.}

Impact of demographic (age, nationality, gender) and economical (income, time, human capital) factors on sport participation (Germany); $n=141,129$; regression analysis, cohort analysis.

Analysis of the development of sports activity over a lifespan (Germany); $n=113,373$, cohort sequence analysis (20 years) and $n=3,012$, longitudinal analysis (20 years); ANOVA
Demographic change and ageing society have only slight impact on sport participation - negative age effects compensated by positive cohort and period effects - cohort effect is the greatest.

Positive effect of income-employed persons less likely to participate in sport - negative effect of age - positive effect of educational level-females less likely to participate than males-Blacks and Hispanics less likely to participate than Whites.

'Inactive' females: did some activity in the past, short term in nature; some did do exercise informally (e.g. exercises at home), some occasionally'Inactive' males: did some sort of sport when they were younger, now greater emphasis on general exercise such as gardening or walking-'Active' group members had a history of participation (women: walking, keep fit, swimming, bowling, yoga and dancing - men: less team orientated nowadays e.g. walking, golf, tennis, badminton), there was a missing of competitiveness of sports.

Increasing age reduces the likelihood of participating in sport-being responsible for housekeeping and undertaking voluntary work reduces the likelihood of participating in sport-frequency of sport participation rises with being more healthy - social and personal capital are important determinants for sport participation.

Women are less likely to participate in sport than men-positive influence of age - education is positively related to the frequency of sport participation-income level has no influence on sport participation-being employed is negatively related to the frequency of sport participation.

Effects of demographic change do not necessarily lead to a reduction in sport inclusion as economic variables such as income and human capital can compensate the effects of demographic change.

Cross-sectional perspective: negative effect of age-however, age-specific rates increased over the years, meaning that also period and cohort effects are crucial. Longitudinal perspective: augmentation of sports activity in half of the analysed cohortsdecreasing activity for men with increasing agefor women, sport activity increases with increasing age, except for the oldest cohort (55-64 years). 
Table 1 (continued)

\begin{tabular}{|c|c|c|}
\hline Author & Aim and method of the study & Central findings \\
\hline Hovemann and Wicker [29] & $\begin{array}{l}\text { Analysis of the determinants influencing sport } \\
\text { participation in the European Union (EU); } \\
n=25,000 ; \text { regression analysis. }\end{array}$ & $\begin{array}{l}\text { European model: age, relationship, Having children } \\
\text { and occupation have a negative effect-education years } \\
\text { and town size have a significant positive influence. }\end{array}$ \\
\hline Klein [35] & $\begin{array}{l}\text { Investigation of the determinants (social class, } \\
\text { occupation, family, age, gender) for physical } \\
\text { activity and different types of sports (Germany); } \\
n=2,002 \text {; Gompertz model }\end{array}$ & $\begin{array}{l}\text { Increasing age is associated with increasing physical } \\
\text { activity (up to } 50 \text { years); especially for } \\
\text { women - higher education is associated with higher } \\
\text { level of exercise - child care reduces exercise levels. }\end{array}$ \\
\hline Hinrichs et al. [28] & $\begin{array}{l}\text { Analysis of effects of socio-demographic and } \\
\text { cardiovascular factors and health status regarding } \\
\text { participation in a cohort of elderly people; } \\
\text { based on [17] (Germany); } n=1,376 \text {; logistic } \\
\text { regression. }\end{array}$ & $\begin{array}{l}\text { More elderly men participate in sporting activities } \\
\text { than women-poor health status has negative impact- } \\
\text { higher educational level has positive effect-lower } \\
\text { socioeconomic status limits access to sports facilities. }\end{array}$ \\
\hline
\end{tabular}

determinants of active involvement in sports activities. To similar findings come Farrell and Shields [25] who state that men are significantly more likely to participate in any kind of sport activity. They also find that men and women have different preferences regarding the type of sporting activity they perform. Women, for example, tend to enjoy aerobics and swimming more than men do. Nonetheless, longitudinal studies reveal that women are participating more in sport which can be shown using period and cohort effects [60].

Investigating migration background, it has to be noted that this variable is treated differently throughout the academic world. Whilst the ethnicity is investigated, e.g. in Northern America and the UK [e.g. 46, 56], the migration background or the nationality is analysed in continental Europe [e.g. 51, 63]. Thus, comparisons should be treated with care. Previous studies indicate in unison that persons with a white ethnic background are more likely to participate in sports $[25,46,56]$, and that people without a migration background tend to take part in sports more often than people with a migration background [51]. A reason among others for this finding is that people with a migration background experience cultural barriers [51]. Those encompass having family commitments; cultural norms of behaviour which are not appropriate to women and older people; sportswear considered immodest; use of fixed gender facilities not possible; instructors and other participants have to be female, the same ethnicity and speaking the same language [54]. Blacks and Hispanics, as found by Humphreys and Ruseski [30], are less likely to participate in physical activity than whites. A broad overview about this topic gives the review by Long et al. [41] which deals with the participation in sport and physical recreation of black and minority ethnic communities in the UK.

A qualitative study [54] with recently retired people investigated internal and external motivators of taking part in sport. Concerning motivators, there are no big differences with regards to gender. Internal motivators came out to be physical benefits, meaning to get fit and healthier as well as controlling weight, social benefits, mental as well as emotional benefits (self esteem and enjoyment of activity), and retaining independence. External motivators to participate in sport were the media and families telling the elderly to be active to stay fit. This relates to the dynamics of sport in today's society and changing social norms and emphasised the treatment of age as a proxy variable (i.e. the social factor is related to it). However, in contrast to the motivators, there are also a number of barriers. Those include costs, health, and physical limitations due to the increasing age.

\section{Economic determinants: income, time, human capital}

Concerning economic indicators, several general tendencies can be observed. First of all, income plays a significant role with regards to sport participation, meaning that individuals with higher income are more likely to participate in sports [5, 25, 30, 32, 33]. However, Lera-López and Rapún-Gárate find that the income level has no influence on sport participation [40]. Secondly, it was shown that time for care of children and relatives impacts regular sport activity negatively $[22,35]$. In contrast, working time (respectively school time) had a positive effect on sport participation [65]. Thirdly, a good educational background was found to have a positive impact on sport participation [25, 30, 33, $40,47,62]$ which is also true for children and adolescents whose parents have a higher educational level [26]. This can be explained by the fact that through a higher educational level, there might be a better understanding of the importance of physical activity and sport [25].

Going more into detail with several studies, Breuer [7] for example conducted a study with the design of a cohort sequence analysis combining demographic and economic factors as determinants for sport participation in Germany. The model contained various demo-economical variables to explain sport participation. As economic variables, income, 
time, and human capital were chosen. Furthermore, a demoeconomical extension was added by choosing the variables age and nationality. Cohort and period effects served as control factors. The results showed that the demographic change and the ageing society have only a small impact on sport participation and that negative age effects could be compensated by positive cohort and period effects. Furthermore, the findings showed that sport participation is significantly influenced by the economic variables income, time, and human capital.

Also with regards to economic factors, Humphreys and Ruseski [30] developed a model regarding economic determinants influencing sport participation and physical activity. They centred their research on two decisions which the consumer has to make: firstly, whether to participate in sport and second, how much time to spend participating in sport. They found that higher income is associated with a higher probability of participating in physical activity. However, time spent in physical activity declines with income, meaning that the economic factors which influence the two decisions to be made are working in opposite directions: factors that lead to an increase in the likelihood of participating in sport generally decrease with the amount of time spent participating in sports. This can be explained by the income-leisure trade off $[21,22]$ and the given time restriction, meaning that a higher income is associated with more working hours and consequently, less leisure time. Furthermore, their results showed that employed persons are slightly less likely to participate in sport than unemployed. This might also be explained by the fact that unemployed people have more leisure time than working people and thereby, can participate more in physical activity. To the same results regarding employment status come Farrell and Shields [25]. Also in this regard, LeraLópez and Rapún-Gárate found that being employed is negatively related to the frequency of sport participation. This applies especially to persons who are self-employed, entrepreneurs, middle managers, farmers, or skilled workers. In contrast, unskilled or semiskilled workers participate less in sports [40].

With regards to social and personal capital determining sport participation, Downward and Riordan [22] conducted a study with the aim of examining social interactions that affect sports participation which was to be measured by the accumulation of social capital. The research design was twofold as they first undertook a cluster analysis to recognise subsamples of individuals with a similar lifestyle (measured inter alia by socio-economic characteristics). The second step was to run a Heckman regression model to examine the decision to participate in sport with the membership of the clusters as a dummy variable. Summarising, they find that investment in personal consumption capital and social capital can increase sport participation as well as frequency of participation. However, there are work-related income-time constraints as for example increasing incomes reduce the frequency of participation. This can again be explained by the income-leisure trade-off model where leisure time decreases with increasing working time [21].

\section{Socio-economic perspective on sport expenditure}

Sport consumption is described and modelled by Downward, Dawson, and Dejonghe [21] as the process of allocating time to participation in activities (meaning frequency and intensity) and then expenditure (meaning equipment, facilities, travel, and clothing). Therefore, after having reviewed studies dealing with sport participation, it seems to be consistent to apply the socio-economic perspective also to sport expenditure of consumers (Table 2). Within this perspective, especially consumers of older age groups are interesting for this review as differences compared to other age groups due to demographic or socioeconomic factors can be investigated. However, according to Downward et al. [21], empirical analyses of sport expenditure are not that extensive as within the participation literature. Furthermore, the methodologies used in this field of research also stand back in comparison to sport participation, meaning that mostly cross-sectional analyses have been conducted. Consequently, there is a lack of longitudinal studies and more appropriate forms of analyses. Thus, adequate forms of measuring age, period, and cohort effects are missing.

Demographic determinants: age and gender

Regarding elderly people, Jost [34] found that the general consumption behaviour depends on several factors, namely the demographic variables age, gender, and health situation, as well as economic determinants such as income. Here again, education can be classified as an indicator as well. As stated by Jost, the general expenditure for service products of the age group over 64 years increased by eight times compared to the equivalent value of 20 years before. Furthermore, the expenditure is higher than those of any other age group [34]. Applying these results to the sport context and the demand for sport consumption, sport expenditure, similar to sport participation, can also be explained from a socio-economical perspective. This is due to the fact that factors such as income as well as educational level are significantly related to increasing expenditure for sporting goods and services $[9,13]$.

In general, with regards to age and consumer behaviour concerning sport expenditure, different studies have shown different findings. Especially cross-sectional studies as well as studies from the 1990s reach the conclusion that due to 
Table 2 Studies on sport expenditure (in chronological order)

\begin{tabular}{|c|c|}
\hline Author & Aim and method of the study \\
\hline Lamb et al. [36] & $\begin{array}{l}\text { Analysis of the influence of sport participation } \\
\text { on sport expenditure and effects of gender, age, } \\
\text { and social class on sport participation } \\
\text { (Great Britain); } n=1,364 \text {; longitudinal study; } \\
t \text {-test and ANOVA. }\end{array}$ \\
\hline $\begin{array}{l}\text { Dardis, Soberon-Ferrer, } \\
\text { and Patro [15] }\end{array}$ & $\begin{array}{l}\text { Investigation of the impact of household socio- } \\
\text { economic determinants (income, family lifecycle, } \\
\text { education, race) on leisure expenditure (USA); } \\
n=2,088 \text { households; tobit analysis. }\end{array}$ \\
\hline Weber et al. [64] & $\begin{array}{l}\text { Analysis of the determinants of sport } \\
\text { expenditure (Germany); } n=2,866 \text {; descriptive. }\end{array}$ \\
\hline $\begin{array}{l}\text { Taks, Renson, and } \\
\text { Vanreusel [58] }\end{array}$ & $\begin{array}{l}\text { Examination of the determinants of consumer } \\
\text { expenses in active sports participation (Belgium) } \\
n=900 \text {; correlation and regression analysis. }\end{array}$ \\
\hline
\end{tabular}

Central findings

Men spend more on sport than women-youngest age group (16-24) spend twice as much as the oldest group $(55+)$ - middle class spends more than working class (but not for men).

Income has significant positive impact - older households spend less than younger ones - number of adults in the household has significant positive effect-education of the household has significant positive impact.

Positive influence of income and educational level-men spend more on sport than women-expenditure decrease with increasing age- expenditure increases with increasing amount of sport activities.

Expenses are directly related to a person's active sport commitment, this especially applies to total time spending - older participants spend more than younger ones - income correlates positively with expenseseducational level and socio-professional status correlate negatively with expenses - time is the strongest determinant to explain expenses in sports - the higher the participation, the more spending.

Davies [16]

Breuer and Hovemann [8] Examination of financial capacity of different sports and if sport expenditure depends on the structure of sport demand (Germany); $n=1,092$; correlation analysis

Cirkel et al. [13]

Lera-López and Rapún-Gárate [38]

Lera-López and Rapún-Gárate [39]

Breuer and Schlesinger [9]

Analysis of income and expenses of elderly people (Germany); Literature review.

Analysis of indicators (time and its constraints and socio-demographic variables) of consumer expenditure on sport (Spain); $n=700$; tobit model.

Analysis of links between participation and expenditure (Spain); $n=700$; ordered probit model to identify frequency of sport participation in the previous year; tobit model to examine consumer expenditure.

Examination of age-dependent consumption and demand for sporting goods with regards to socio-economic and demographic determinants (Germany); $n=24,515$; ANOVA.

Lera-López and Rapún-Gárate [40]

Wicker, Breuer, and Pawlowski [66]
Analysis of socio-demographic and economic variables regarding sport participation and consumer expenditure (Spain); $n=700$; ordered probit models.

Analysis of the predictors (income, human capital, years of participation, level of performance, time of participation, age, and gender) of sport expenditure of members of non-profit sports clubs (Germany); $n=10,013$; regression analysis
Frequency of sport participation is no explanatory variable for increased spending on sport-related goods and services.

Men's individual expenditure is higher than women'samount of money at free disposal and amount of physical activity are predictors for sport expenditureage and motivation have no effect.

Education and income influence sport expenditure - men spend more money on sports than women.

Women spend less on sports than men-people with higher level of education spend more on sports - age and size of household have strong negative association with sports expenditure-age: non-linear relationshiplarger households report lower per capita spendingpopulation size is a strong predictor.

Participation decreases being female and/or employed, but increases with age - spending decreases being female, but increases with education and incomeconsumer expenditure on sports is determined by gender, education, and income level.

Demand for sporting goods does not differ significantly throughout the different age groups - men spend more on sporting goods than women-positive impact of educational level - expenditure rises with higher income.

Men spend more on sport than women-age is negatively related to sport consumption - educational level is positively related to sport consumption-influence of income on sport expenditure-employed spend more on sports as well as higher skilled workers and managers.

Sport specific analyses: big differences in expenditure between sports (e.g. badminton vs. equestrian)personal income, level of performance, and weekly time of participation are the main predictors of sport specific expenditure. 
age, there is a significant decrease in sport engagement and with this, also in sport expenditure [13, 64]. On the other side, it was shown that there is no linear relationship between age and the amount of sport expenditure [8-10].

Regarding gender differences, generally speaking, men tend to spend more money on sports than women $[9,36$, $38-40,57]$. This can be explained by the fact that women are also less active in sports than men [9]. As mentioned, the effects of age and education cannot be described that consistently as there are different findings from several authors. Lamb et al. [36] found that in the UK, younger people spend more on sport whereas Taks [58] and Oga [44] reported the opposite for Belgium and Japan, respectively. Furthermore, Taks also found that spending on sporting goods might decrease with educational level [58] which again is contradictory to findings of other authors $[9$, 13]. In this regard, Breuer and Schlesinger came to know that educational level does have a significant influence on demand for sporting goods; however, a continuous increase of expenditure with higher educational level cannot be proved. A higher level of education was found to be related to higher spending on sports by Lera-López and RapúnGárate [38]. Further, Breuer and Schlesinger [9] detected that there are interaction effects between age and gender, especially for the age group of the over 70 years old. Here, expenditure for men increased distinctly whereas demand for sporting goods decreased for women in this age group.

\section{Economic determinants}

Spending on sports appears to be related to income, meaning that with a rising income, also the sport expenditure goes up [21]. This is also found by Breuer and Schlesinger [9] who state that the relation between sport expenditure and net income is significant. Persons with a higher income and by this more financial potential can spend more money on sport. This has already been found in previous research by Weber [64] and also by Lera-López and Rapún-Gárate whose results of ordered probit models show that the influence of income on sport consumption is statistically significant [40]. Furthermore, they find that being employed is positively related to sport consumption but negatively related to sport participation. Also, sport expenditure is lower among unskilled or semiskilled workers in comparison to managers or skilled workers.

\section{Conclusion}

Having reviewed different research papers with regard to the determinants of sport participation and sport expenditure, both demographic variables such as age, gender, nationality, and ethnic background, respectively, as well as socio-economical variables such as income, time, human capital, profession, social status, and family status play an important role. It was shown that the demand for sport has a dynamic character with regards to different sports and over a lifespan and that especially age plays a crucial role investigating physical activity and sport expenditure.

A comparative study of determinants of sport participation and consumer expenditure [39] shows pertaining to sport participation that mainly the demographic determinants age and gender as well as occupation influence the frequency in sport participation (decreasing for females and employed, increasing with age), whereas consumer expenditure on sports is mainly determined by gender, education, and income level (spending decreases for females but increases with education and income). There is thus a direct relationship between sport participation and expenditure which is, however, facilitated by the access to money in the form of income.

Nonetheless, the amount of research which has been conducted with regards to sport participation is much larger than the research on sport expenditure. Also, the different methods applied throughout the studies and the choice of different variables makes it hard to compare the results. Nevertheless, certain general similarities can be detected, e.g. that for physical activity, men are more likely to participate in sports than women. The same is the case for sport expenditure, meaning that men spend more on sports than women.

However, next to the reviewed and mentioned studies and variables, future research could additionally include the motivational factors for sport participation as well as barriers which might be reasons for non-participation. These aspects have already been researched by Sport England [54] for recently retired people and then used for policy implications. Consequently, this field of research should be expanded to get to know what the motives for sport participation or non-participation, respectively, are. As a lack of longitudinal studies was observed, it is suggested to focus on this type of studies, as they have methodological advantages over cross-sectional studies concerning age, period, and cohort effect, notwithstanding the application of cohort-sequence analyses or multi-point cross-section analyses. Future research should go beyond mere descriptive results but use multivariate analysis tools like regressions as they can portray the impact of the different indicators best.

\section{References}

1. Alexandris K, Carroll B (2000) A demographic model of recreational sport participation: planning application for recreational sport programs (mass participation) in Greece. Exer Soc J Sport Sci 24:36-47 
2. Allender S, Cowburn G, Foster C (2006) Understanding participation in sport and physical activity among children and adults: a review of qualitative studies. Health Educ Res 21(6):826-835

3. Baker J, Fraser-Thomas J, Dionigi R, Horton S (2010) Sport participation and positive development in older persons. European Rev Aging Phys Act 7(1):3-12

4. Becker GS (1964) Human capital. A theoretical and empirical analysis, with special reference to education General series, vol 80. Columbia University Press, New York, USA

5. Berger IE, O'Reilly N, Parent MM, Séguin B, Hernandez T (2008) Determinants of sport participation among Canadian adolescents. Sport Manage Rev 11(3):277-307. doi:10.1016/ S1441-3523(08)70113-X

6. Breuer C (2003) Entwicklung und Stabilität sportlicher Aktivität im Lebenslauf-zur Rolle von Alters-, Perioden- und Kohorteneffekten [Development and stability of sports activity in the course of life]. Sportwissenschaft-German J Sport Sci 33(3):263-279

7. Breuer C (2006) Sportpartizipation in Deutschland305ein demoökonomisches Modell [Sports participation in Germany305a demo-economic model]. Sportwissenschaft-German J Sport Sci 36(3):292-305

8. Breuer C, Hovemann G (2002) Individuelle Konsumausgaben als Finanzierungsquelle des Sports. In: Horch H-D, Heydel J, Sierau A (eds) Finanzierung des Sports. Probleme und Perspektiven. Beiträge des 2. Kölner Sportökonomie-Kongresses. Meyer and Meyer, Aachen, pp 61-79

9. Breuer C, Schlesinger T (2006) Altern und Sportartikelnachfrage [Ageing and the demand for sporting goods]. Sport und Gesellschaft-Sport Soc 3(2):175-197

10. Breuer C, Wicker P (2007) Körperliche Aktivität über die Lebensspanne. In: Fuchs R, Göhner W, Seelig H (eds) Aufbau eines körperlich aktiven Lebensstils: Theorie, Empirie und Praxis. Sportpsychologie, vol 4. Hogrefe, Göttingen, pp 89-107

11. Breuer C, Wicker P (2008) Demographic and economic factors concerning the conclusion in the German sport system-a micro-analysis of the year 1985 to 2005. European J Sport Soc 5(1):33-42

12. Breuer C, Wicker P (2009) Decreasing sports activity with increasing age? Findings from a 20-year longitudinal and cohort sequence analysis. Res Q Exerc Sport 80(1):22-31

13. Cirkel M, Hilbert J, Schlak C (2004) Produkte und Dienstleistungen für mehr Lebensqualität im Alter [Products and services for more life quality in older age]. Institut für Arbeit und Technik, Gelsenkirchen

14. Curtis J, White P, McPherson B (2000) Age and physical activity among Canadian women and men: findings from longitudinal national survey data. J Aging Phys Activ 8:1-19

15. Dardis R, Soberon-Ferrer H, Patro D (1994) Analysis of leisure expenditures in the United States. J Leis Res 26(4):309-321

16. Davies L (2002) Consumers' expenditure on sport in the UK: increased spending or underestimation? Manag Leis 7:83-102

17. Diehm C (2002) GetABI: Deutsche epidemiologische Studie zum Knöchel Arm Index bei älteren Patienten in hausärztlicher Betreuung [German epidemiological trial on ankle brachial index for elderly patients in family practice to dedect peripheral arterial disease, significant marker for high mortality]. VASA 31(4):241248

18. Dishman RK (1988) Determinants of physical activity and exercise for persons 65 years of age or older. In: Spirduso WW, Eckert HM (eds) Physical activity and aging. American Academy of Physical Education, Kansas City, pp 140-162

19. Dishman RK, Sallis JF, Orenstein DR (1985) The determinants of physical activity and exercise. Public Health Rep 100(2):158-171

20. Donat Tuna H, Ozcan Edeer A, Malkoc M, Aksakoglu G (2009) Effect of age and physical activity level on functional fitness in older adults. European Rev Aging Phys Act 6(2):99-106
21. Downward P, Dawson A, Dejonghe T (2009) Sport economics. THEORY, evidence and policy. Butterworth-Heinemann, Oxford

22. Downward P, Riordan J (2007) Social interactions and the demand for sport: an economic analysis. Contemp Econ Policy 25(4):518-537

23. Eatwell J, Milgate M, Newman P (1989) Social economics. W. W. Norton, New York

24. Council of Europe (1992) European sports charter. European Union, Strasbourg

25. Farrell L, Shields MA (2002) Investigating the economic and demographic determinants of sporting participation in England. J R Stat Soc B 165(2):335-348

26. Federico B, Falese L, Capelli G (2009) Socio-economic inequalities in physical activity practice among Italian children and adolescents: a cross-sectional study. J Public Health 17(6):377-384

27. Gratton C, Taylor P (2000) Economics of sport and recreation. Spon Press, New York

28. Hinrichs T, Trampisch U, Burghaus I, Endres H, Klaaßen-Mielke R, Moschny A, Platen P (2010) Correlates of sport participation among community-dwelling elderly people in Germany: a crosssectional study. European Rev Aging Phys Act. doi:10.1007/ s11556-010-0063-8

29. Hovemann G, Wicker P (2009) Determinants of sport participation in the European Union. European J Sport Soc 6(1):49-57

30. Humphreys BR, Ruseski JE (2006) Economic determinants of participation in physical activity and sport. Unpublished Working Paper Series No 06-13. International Association of Sports Economists

31. Humphreys BR, Ruseski JE (2007) Participation in physical activity and government spending on parks and recreation. Contemp Econ Policy 25(4):538-552

32. Humphreys BR, Ruseski JE (2009) The economics of participation and time spent in physical activity (working paper 2009-09). University of Alberta, Department of Economics, Institute for Public Economics, Edmonton

33. Ifedi F (2008) Sport participation in Canada, 2005. Statistics Canada: Culture, Tourism and the Centre for Education Statistics, Ottawa

34. Jost T (2009) Sportbezogene Ausgaben älterer Menschen. Eine Untersuchung aus soziologischer und ökonomischer Perspektive. [Sport expenditures of elderly people. An investigation from a sociological and economical perspective]. GRIN, Norderstedt

35. Klein T (2009) Determinanten der Sportaktivität und der Sportart im Lebenslauf. Kölner Zeitschrift für Soziologie und Sozialpsychologie 61(1):1-32

36. Lamb LL, Asturias LP, Roberts K, Brodie DA (1992) Sports participation-how much does it cost? Leis Stud 11(1):19-29

37. Lamprecht M, Stamm H-P (2000) Sport Schweiz 2000. Sportaktivität und Sportkonsum der Schweizer Bevölkerung. SOV, STG, LSSFB, Basel, Bern, Zürich

38. Lera-López F, Rapún-Gárate M (2005) The determinants of consumer expenditure on sports: a tobit model. In: Papanikos GT (ed) International research on sports economics and production. Athens Institute for Education and Research, Athens, pp 61-78

39. Lera-López F, Rapún-Gárate M (2005) Sports participation versus consumer expenditure on sport: different determinants and strategies in sports management. Eur Sport Manag Q 5 (2): $167-186$

40. Lera-López F, Rapún-Gárate M (2007) The demand for sport: sport consumption and participation models. J Sport Manage 21 (1):103-122

41. Long J, Hylton K, Spracklen K, Ratna A, Bailey S (2009) A systematic review of the literature on black and minority ethnic communities in sport and physical recreation. Carnegie Research Institute, Leeds Metropolitan University, Leeds

42. Mayer KU, Huinink J (1990) Alters-, Perioden- und Kohorteneffekte in der Analyse von Lebensläufen oder: Lexis ade? In: Mayer KU (ed) 
Lebensläufe und sozialer Wandel (Kölner Zeitschrift für Soziologie und Sozialpsychologie, Sonderheft 31). Westdeutscher Vertrag, Opladen, pp 442-459

43. Mechling H, Netz Y (2009) Aging and inactivity - capitalizing on the protective effect of planned physical activity in old age. European Review of Aging and Physical Activity 6(2):89-97

44. Oga J (1998) Business fluctuation and the sport industry in Japan: an analysis of the sport industry from 1986 to 1993 . J Sport Manage 12(1):63-75

45. Pohjolainen P, Heikkinen E (1989) A longitudinal study of the physical activity of retired people. In: Harris R, Harris S (eds) Physical activity, aging and sports, vol 1. Scientific and medical research. Center for the Study of Aging, Albany, NY, pp 219-224

46. Pratt M, Macera CA, Blanton C (1999) Levels of physical activity and inactivity in children and adults in the united states: current evidence and research issues. Med Sci Sports Exerc 31(11, Supplement 1):526-533

47. Scheerder J, Thomis M, Vanreusel B, Lefevre J, Renson R, Vanden Eynde B, Beunen GP (2006) Sports participation among females from adolescence to adulthood a longitudinal study. Int Rev Sociol Sport 41(3/4):413-430

48. Schoenborn C, Barnes P (2002) Leisure-time physical activity among adults: United States 1977-1978 - advance data from vital and health statistics (no. 325). National Center for Health Statistics, Hyattsville, MD

49. Seabra AF, Mendonca DM, Thomis MA, Malina RM, Maia JA (2007) Sports participation among Portuguese youth 10 to 18 years. J Phys Activ Health 4(4):370-380

50. Slingerland AS, van Lenthe FJ, Jukema JW, Kamphuis CBM, Looman C, Giskes K, Huisman M, Narayan KMV, Mackenbach JP, Brug J (2007) Aging, retirement, and changes in physical activity: prospective cohort findings from the globe study. Am J Epidemiol 165(12):1356-1363. doi:10.1093/aje/kwm053

51. Snape R, Binks P (2008) Re-thinking sport: physical activity and healthy living in British south Asian Muslim communities. Manag Leis 13(1):23-35

52. Spirduso WW, Eckert HM (1989) Physical activity and aging. American Academy of Physical Education papers no. 22. Human Kinetics Books for the American Academy of Physical Education., Kansas City, Missouri
53. SportEngland (2004) Driving up participation. Sport England, London

54. SportEngland (2006) Understanding participation in sport: what determines sports participation among recently retired people? Sport England, London

55. SportEngland (2009) Active people survey 2008/2009: participation. Sport England, London

56. Stamatakis E, Chaudhury M (2008) Temporal trends in adults' sports participation patterns in England between 1997 and 2006: the health survey for England. Br J Sports Med 42(11):901-908. doi:10.1136/bjsm.2008.048082

57. Taks M, Renson R, Vanreusel B (1995) Social stratification in sport: a matter of money or taste? Eur J Sport Manag 2(1):4-14

58. Taks M, Renson R, Vanreusel B (1999) Consumer expenses in sport: a marketing tool for sports and sports facility providers? Eur J Sport Manag 6(1):4-18

59. Taks M, Scheerder J (2006) Youth sports participation styles and market segmentation profiles: evidence and applications. Eur Sport Manag Q 6(2):85-121

60. van Mechelen W, Twisk JWR, Post GB, Snel J, Kemper HCG (2000) Physical activity of young people: the Amsterdam Longitudinal Growth and Health study. Med Sci Sports Exerc 32:1610-1616

61. Van Tuyckom C, Scheerder J (2008) Sport for all? Social stratification of recreational sport activities in the EU-27. Kinesiol Slov 14(2):54-63

62. Wagner G, Ardelt M, Ott N (1990) Bevölkerungsentwicklung und Sportpotentiale bis zum Jahr 2000. Eine mikroanalytische Simulationsstudie. In: Anders G (ed) Vereinssport an der Wachstumsgrenze? Sport in der Krise der Industriegesellschaften. Reihe Sport-Ökonomie, Band 2. Verlag am Steinberg Gerd May, Witten, pp 124-164

63. Walseth K (2008) Bridging and bonding social capital in sportexperiences of young women with an immigrant background. Sport Educ Soc 13(1):1-17

64. Weber W, Schnieder C, Kortlüke N, Horak B (1995) Die wirtschaftliche Bedeutung des Sports. Hofmann, Schorndorf

65. Wicker P, Breuer C, Pawlowski T (2009) Promoting sport for all to age-specific target groups: the impact of sport infrastructure. Eur Sport Manag Q 9(2):103-118

66. Wicker P, Breuer C, Pawlowski T (2010) Are sports club members big spenders? Findings from sport specific analyses in Germany. Sport Management Review 13(3):214-224 